\title{
Psychological and psychosexual aspects of vulvar vestibulitis
}

\section{Original article}

\author{
David Nunns, D Mandal
}

\begin{abstract}
Aims: To objectively assess the psychological and psychosexual morbidity of patients with vulvar vestibulitis.

Methods: 30 patients with variable degrees of vulvar vestibulitis were recruited from a vulval clinic. Each patient underwent a detailed history and clinical examination. Friedrich's criteria were used for the diagnosis of vulvar vestibulitis. Standardised questionnaires to assess psychological and psychosexual function were completed by the patient before review. These questionnaires were the STAI and a modified psychosexual questionnaire introduced by Campion.

Results: Patients experienced considerable psychological dysfunction compared with controls. All aspects of psychosexual dysfunction were affected.

Conclusions: When managing patients, psychosexual and psychological issues must be considered in addition to other conventional types of therapy. Vulvar vestibulitis may be a risk factor for developing psychosexual complications including vaginismus, low libido, and orgasmic dysfunction. Consideration of these factors must be an integral part of the management of patients with all chronic vulval conditions.

(Genitourin Med 1997;73:541-544)
\end{abstract}

Keywords: vulvar vestibulitis; psychosexual problems; psychological problems

\section{Introduction}

Vulvar vestibulitis is an unexplained inflammatory condition of the vestibule characterised by burning, soreness, and entry dyspareunia. ${ }^{1}$ The precise cause of symptoms has not yet been elucidated; however, speculated aetiologies include contact dermatitis, human papilloma virus infection and recurrent candidiasis. ${ }^{2-4}$ In the absence of an identifiable aetiology, treatment is often based on symptomatic measures which commonly include topical corticosteroids, emollients, and strict vulval hygiene practice. Surgery and intralesional or systemic interferons have been used to treat difficult cases of vulvar vestibulitis with variable success rates. ${ }^{56}$ For a minority, however, no treatment will alleviate symptoms and the outlook for these patients will be poor.

Not only is the condition painful and disabling, but it has many far reaching implications for patients in terms of their sexuality, self esteem, and relationships. We objectively assessed the psychological and psychosexual morbidity of patients with vulvar vestibulitis recruited from a vulval clinic.

Department of
Obstetrics and
Gynaecology, Leicester
Royal Infirmary,
Leicester LE1 5WW
D Nunns
The Vulval Clinic,
Bolton Centre for
Sexual Health, Bolton
General Hospital,
Farnworth, Bolton
BL4 0JR
D Mandal
Correspondence to:
Dr D Nunns.
Accepted for publication
25 April 1997

\section{Methods}

For this study, 30 patients with variable tively recruited over a 14 month period subject to approval from the local district ethics committee. Each patient underwent a detailed history and clinical examination. Friedrich's criteria were used for the diagnosis of vulvar vestibulitis. ${ }^{1}$ These included (1) severe pain on vestibular touch or attempted vaginal entry (that is, entry dyspareunia), (2) tenderness to pressure localised within the vestibule, and (3) the physical findings of erythema of various degrees of vulvar vestibulitis were consecu- degrees. The degree of vestibular tenderness was judged by the swab test introduced by Goetsch. ${ }^{7}$ In this test a water moistened cotton wool swab is used to touch the vestibule at six different sites and the response of the patients is documented. At the start of the test, patients are asked whether touch at an adjacent site feels normal and not painful and are then asked to compare sensations at the different sites. The swab is rolled over each site avoiding rubbing and five grades of response are considered: (0), normal sensation; (1), unpleasant scratchy sensation; (2), painful sharp sensation; (3), patient acknowledges pain and is noted to flinch; (4), patient notes considerable pain and recoils. The patient's subjective answers provide the means for differentiating between grades (0) to (2). Patients were considered to have severe vulvar vestibulitis with swab test grades (3) and (4).

Before the clinical consultation, patients were given a confidential questionnaire to complete. A psychological assessment of patients with vulvar vestibulitis was made using the Spielberger Manual for the State-trait Anxiety Inventory (STAI). ${ }^{8}$ The STAI refers to two aspects of anxiety states, the trait anxiety (T-Anxiety) and the state anxiety (S-Anxiety). The T-Anxiety refers to relatively stable individual differences in anxiety proneness-that is, to differences between people in the tendency to perceive stressful situations as dangerous or threatening and to respond to such situations with elevations in the intensity of their S-Anxiety reactions. T-Anxiety may also reflect individual differences in the frequency and intensity with which anxiety states have been manifested in the past, and in the probability that S-Anxiety will be experienced in the future. The stronger the anxiety trait, the more 
Table 1 Results of the STAI assessment for patients and controls

\begin{tabular}{|c|c|c|}
\hline & $\begin{array}{l}\text { State score } \\
\text { (95\% confidence } \\
\text { intervals) }\end{array}$ & $\begin{array}{l}\text { Trait score } \\
\text { (95\% confidence } \\
\text { intervals) }\end{array}$ \\
\hline $\begin{array}{l}\text { Subjects } \\
(\mathrm{n}=30) \\
\text { Controls } \\
(\mathrm{n}=10) \\
\mathrm{p} \text { Value } \\
\text { Long term pain } \\
(\mathrm{n}=21) \\
\text { Short term pain } \\
(\mathrm{n}=9) \\
\mathrm{p} \text { Value } \\
\text { Mild/mod pain } \\
(\mathrm{n}=19) \\
\text { Severe pain } \\
(\mathrm{n}=11) \\
\mathrm{p} \text { Value }\end{array}$ & $\begin{array}{l}42 \cdot 20^{\star} \\
(39 \cdot 73-44 \cdot 67) \\
32 \cdot 30 \\
(27 \cdot 85-36 \cdot 75) \\
0 \cdot 001 \\
43 \cdot 44 \\
(37 \cdot 59-49 \cdot 30) \\
48 \cdot 60 \\
(36 \cdot 88-60 \cdot 32) \\
0 \cdot 45 \\
47 \cdot 86^{\star} \\
(46 \cdot 30-49 \cdot 42) \\
39 \cdot 87 \\
(35 \cdot 99-43 \cdot 75) \\
0 \cdot 002\end{array}$ & $\begin{array}{l}44 \cdot 30^{\star} \\
(42 \cdot 79-45 \cdot 81) \\
36 \cdot 89 \\
(34 \cdot 02-39 \cdot 76) \\
<0 \cdot 001 \\
46 \cdot 69 \\
(42 \cdot 41-50 \cdot 97) \\
43 \cdot 40 \\
(38 \cdot 0-48 \cdot 81) \\
0 \cdot 35 \\
46 \cdot 90 \\
(45 \cdot 83-47 \cdot 97) \\
45 \cdot 40 \\
(42 \cdot 54-48 \cdot 26) \\
0 \cdot 34\end{array}$ \\
\hline
\end{tabular}

*Significant result.

probable that the individual will experience more intense elevations in S-Anxiety in a threatening situation. People with high $\mathrm{T}$ Anxiety exhibit S-Anxiety elevations more frequently than low T-Anxiety individuals because they intend to interpret a wider range of situations as dangerous or threatening. High T-Anxiety people are also more likely to respond with greater increases in the intensity of S-Anxiety in situations that involve interpersonal relationships and threaten self esteem. The STAI has been used extensively in research and clinical practice. It comprises self report scales for measuring state and trait anxiety. The S-Anxiety scale (STAI Form Y-1) consists of 20 statements that evaluate how respondents feel "right now, at this moment". The T-Anxiety scale (STAI Form Y-2) consists of 20 statements that assess how people generally feel. The essential qualities evaluated by the STAI S-Anxiety scale are feelings of apprehension, tension, nervousness, and worry. Each STAI item is given a score of 1 to 4 and an overall score is given for the state and the trait forms. The higher the scores the greater the degree of anxiety when compared with "normal controls". The scores vary from a minimum of 20 to a maximum of 80.

In addition to the STAI, patients were given a modified psychosexual questionnaire introduce by Campion. ${ }^{9}$ This brief questionnaire outlines six aspects of the patients' sexual lifestyle. The aspects of sexuality investigated were: (1) frequency of spontaneous sexual

Table 2 Results of the psychosexual questionnaire

\begin{tabular}{|c|c|c|c|c|}
\hline \multicolumn{2}{|c|}{ Question } & \multirow{2}{*}{$\begin{array}{l}\text { Patients } \\
\text { (95\% confidence } \\
\text { intervals) }(n=30) \\
2 \cdot 53 \\
(1 \cdot 88-3 \cdot 12)\end{array}$} & \multirow{2}{*}{$\begin{array}{l}\begin{array}{l}\text { Controls } \\
(n=10)\end{array} \\
2 \cdot 86 \\
(1 \cdot 32-4 \cdot 40)\end{array}$} & \multirow{2}{*}{$\frac{p \text { Value }}{0.64}$} \\
\hline (1) & $\begin{array}{l}\text { How often do you develop any } \\
\text { spontaneous interest in sex, not } \\
\text { elicited by a sexual partner? }\end{array}$ & & & \\
\hline (2) & How often do you make love? & $\begin{array}{l}2 \cdot 81 \\
(2 \cdot 11-3 \cdot 51)\end{array}$ & $\begin{array}{l}4 \\
(2 \cdot 69-5 \cdot 3)\end{array}$ & $0 \cdot 11$ \\
\hline (3) & $\begin{array}{l}\text { How often do you become } \\
\text { sexually aroused when you } \\
\text { make love? }\end{array}$ & $\begin{array}{l}2 \cdot 68^{\star} \\
(2 \cdot 15-3 \cdot 21)\end{array}$ & $\begin{array}{l}4 \\
(2 \cdot 69-5 \cdot 3)\end{array}$ & 0.03 \\
\hline (4) & $\begin{array}{l}\text { How often do you achieve an } \\
\text { orgasm when you are making } \\
\text { love? }\end{array}$ & $\begin{array}{l}2 \cdot 14 \\
(1 \cdot 51-2 \cdot 77)\end{array}$ & $\begin{array}{l}2 \cdot 57 \\
(1 \cdot 72-3 \cdot 42)\end{array}$ & 0.47 \\
\hline (5) & $\begin{array}{l}\text { How often do you have negative } \\
\text { feelings about making love? }\end{array}$ & $\begin{array}{l}2 \cdot 3^{\star} \\
(1 \cdot 81-2 \cdot 79)\end{array}$ & $\begin{array}{l}1 \cdot 29 \\
(0 \cdot 72-1 \cdot 86)\end{array}$ & 0.04 \\
\hline (6) & $\begin{array}{l}\text { Do you have sufficient vaginal } \\
\text { lubrication when you make love? }\end{array}$ & $\begin{array}{l}2 \cdot 26^{\star} \\
(1 \cdot 71-2 \cdot 81)\end{array}$ & $\begin{array}{l}3 \cdot 29 \\
(2 \cdot 35-4 \cdot 23)\end{array}$ & 0.05 \\
\hline
\end{tabular}

^Significant result. interest; (2) frequency of sexual intercourse; (3) frequency of adequate vaginal lubrication and sexual arousal with intercourse; (4) frequency of orgasm with intercourse; (5) frequency of negative feelings towards intercourse; and (6) the presence of vaginal lubrication during intercourse. For questions (1) and (2), subjects were allowed to choose one point along a 7 point scale to describe the appropriate response. The following inscriptors were used: $0=$ never; $1=$ rarely; $2=$ once a month; $3=$ between two and four times a month; $4=$ once a week; $5=$ between two and six times week; $6=$ daily. For questions (3) to (6) inclusive, a five point scale was used with the following inscriptors; 0 $=$ never; $1=$ rarely $(25 \%) ; 2=$ occasionally $(50 \%) ; 3=$ frequently $(75 \%) ; 4=$ usually. Control questionnaires were filled in by women attending the department's family planning clinic for routine cervical screening who had had previously normal smears. The questionnaires were given to the women before their smear test. After completion of the questionnaire, a smear was taken and vulvar vestibulitis was excluded using Friedrich's criteria. ${ }^{1}$ Continuous data were analysed using Student's $t$ test with confidence intervals.

\section{Results}

A total of 30 patients with vulvar vestibulitis completed both questionnaires. All patients were cooperative and completed the questionnaires. The median ages of the patients and controls was 30 (range 18-40) and 32 years (range 20-37) respectively. Both the trait and the state anxiety scores for patients were significantly higher than controls (table 1). Spearman's rank correlation coefficient between the trait and state scores was 0.72 which was similar to the control group (0.7).

The relation between the psychological morbidity and the severity and duration of the symptoms among patients was examined. Patients with short term pain (less than 6 months in duration) were compared with patients with long standing pain. There was no significant difference between the trait and state scores among the two groups of patients, although there was a trend of an increase in the state anxiety score for the patients with short term symptoms. In addition, patients with severe vestibular pain were compared with patients with lesser degrees of pain as judged by the clinician. Paradoxically, patients with severe symptoms had significantly lower state and trait scores than patients with mild or moderate symptoms.

The response of the two cohorts of patients to the psychosexual questionnaire are given in table 2. The first psychosexual question related to the patient's spontaneous sexual interest not elicited by an approach from a sexual partner as opposed to interest arising once a sexual encounter has begun. Patients had less spontaneous interest in sex than controls although this was not significant. Questions (2) to (4) inclusive referred to sexual function and response. Patients had sexual 
intercourse and became aroused significantly less frequently than controls and experienced fewer orgasms than controls although not significantly with most patients only "occasionally" having an orgasm. Question (5) referred to the patient's feelings towards the sexual aspects of her relationship and she was asked to outline the frequency of negative thoughts. Question (6) related to the degree of vaginal lubrication. Patients had significantly more negative thoughts towards sex and less vaginal lubrication during sex than controls.

\section{Discussion}

Patients with vulvar vestibulitis do not simply have dyspareunia and vulval soreness as their presenting complaints. The condition has many major implications including its effects on lifestyle, relationships, sexuality, and self image. Where psychological assessments have been carried out by other authors, considerable morbidity is experienced universally by patients compared with controls. ${ }^{1011}$ It is somewhat surprising, therefore, that in addition to other conventional treatments, the assessment and management of psychological and psychosexual dysfunction in these patients is rarely addressed.

Our results indicate that not only do patients suffer an increase in anxiety at the time of consultation (as judged by the increase in the S-Anxiety scales), but they have an increase in the proneness to anxiety (as judged by the increase in the T-Anxiety scales). An increase in the T-Anxiety scale is associated with an increased ability to perceive situations as life threatening and is also associated with low self esteem. ${ }^{8}$ These underlying characteristic traits in patients may play a role in the clinical manifestations of disease. Both scores were the same as for patients the night before undergoing surgery.12 Patients with chronic backache have significantly higher levels of anxiety with long term pain as opposed to short term pain and it would be anticipated that this relationship between the duration of symptoms and the degree of anxiety would be seen among our patients; however, there was no significant difference between the two groups. ${ }^{13}$ Paradoxically, there were greater state and trait scores for patients with mild and moderate symptoms compared with those with severe symptoms. This may reflect inaccuracies in judging the degree of pain experienced by the patient using the swab test assessment.

Compared with control patients, all aspects of sexual activity and practice were adverse in patients with vulvar vestibulitis. It is of concern that patients had significantly less sexual arousal and negative feelings towards sexual intercourse than controls. Sexual response and sexual interest are relatively independent and a fall in the latter has been shown to be indicator of significant psychosexual morbidity and is associated with poor self esteem. ${ }^{14}$ It is interesting to note that although dyspareunia is mainly the presenting feature of vulvar vestibulitis, many of the women in this study reported to have sexual intercourse and that the frequency of intercourse among our group of patients was not significantly lower than that of the control group. One limitation of this study was the recruitment of suitable controls. We considered women attending our family planning clinic for routine cytological smears to be best suited as they were closely matched for age to the study group. Women with dyskaryotic smears were excluded as these women are known to suffer psychosexual and psychological upset. ${ }^{9}$

Many studies of patients with vulvar vestibulitis have demonstrated a physical component to the disease and many factors have been implicated in its development. ${ }^{2-4}$ In Goetsch's prevalence series, $15 \%$ of patients attending gynaecology outpatient clinics satisfied the criteria for vulvar vestibulitis; however, an additional $18 \%$ of patients who were asymptomatic complained of pain when the vestibule area was touched during the swab test. ${ }^{7}$ In addition to these undefined physical factors, psychosexual factors may perpetuate symptoms. Anxiety may cause decreased sexual arousal, inadequate lubrication, and difficulty achieving an orgasm. The subsequent dyspareunia associated with these factors and the presence of physical disease may propagate negative feelings towards sex leading to further anxiety and apprehension. This pattern of events may perpetuate vestibular inflammation as a result of the mechanical irritation of sex leading into a cycle of symptoms as described by Schover et al. ${ }^{15}$ In their series, the treatment response rate following perineoplasty for vulvar vestibulitis was further increased by preoperative psychological assessment and postoperative psychosexual therapy. There are few reports of vulvar vestibulitis among celibate women. ${ }^{16}$

When managing patients, these psychosexual and psychological issues must be considered in addition to other conventional types of therapy. Counselling patients, reassurance, and even psychological and psychosexual referrals are therefore an important part of managing patients as a whole. Clinicians should be aware that vulvar vestibulitis is a risk factor for developing considerable psychosexual complications including vaginismus, low libido, and orgasmic dysfunction. The potential ramifications of the disease on the patient and her social and sexual life must never be underestimated and consideration of these factors must be an integral part of patient management.

1 Friedrich EG. Vulvar vestibulitis syndrome. $\mathcal{f}$ Reprod Med 1987;32:110-4.

2 McKay M. Subsets of vulvodynia. f Reprod Med 1988;

3 Turner MLC, Marinoff SC. Association of human papilloma virus with vulvodynia and the vulvar vestibulitis syndrome. F Reprod Med 1988;33:533-7.

4 Ashman RB, Ott AK. Autoimmunity as a factor in recurrent vaginal candidosis and the minor vestibular gland syndrome. F Reprod Med 1989;34:264-6.

5 Bornstein J, Zarfati D, Goldik Z, Abramovici H Perineoplasty compared to vestibuloplasty for severe vulvar vestibulitis. $B r f$ Obstet Gynaecol 1995;102:652-5.

6 Horowitz BJ. Interferon for condylomatous vulvitis. Obstet Gynecol 1989;73:Pt 1, 445-8.

7 Goetsch MF. Vulvar vestibulitis: prevalence and historic features in a general gynaecologic practice population. 
Am 7 Obstet Gynecol 1991;164 Pt 1:1606-11.

8 Spielberger CD. Anxiety assessment: manual for the stait-trait anxiety inventory. Consulting Psychologists Press, 1983. 172

9 Campion MJ. Psychosexual trauma of an abnormal smear. Brf Obstet Gynaecol 1988;95:175-81.

10 Jadresic D, Barton S, Neill S, Staughton R, Marwood R. Psychiatric morbidity in women attending a clinic for vulval problems - is there a higher rate in vulvodynia? Int $\mathcal{F}$ STD and AIDS 1993;4:237-9.

11 Stewart DE Chantal IE, Fong IW, Tessler KM Psychosocial aspects of chronic, clinically inconfirmed vulvovaginitis. Obstet Gynecol 1994;76:pt 1 852-60.
12 Johnstone $M$ Anxiety in surgical patients. Psychol Med 1980;10:145-52.

13 Renaer M, Vertommen H, Nijs P, Wagemans L, Van Hemelrijck T. Psychological aspects of pelvic pain in women. Am $\mathcal{F}$ Obstet Gynecol 1979;134:75-8.

14 Bancroft J, Tyrer G, Warner R. The classification of sexual problems in women. Br $\mathcal{F}$ Sex Med 1982;9:30-7.

15 Schover LR, Youngs DD, Cannata RN. Psychosexual aspects of the evaluation and management of vulvar vestibulitis. Am $\mathcal{f}$ Obstet Gynaecol 1991;167:630-6.

16 Perniciaro C, Bustamante AS, Gutierrez MM. Two cases of vulvodynia with unusual causes. Acta Derm Venereol Stockh 1993;73:227-8. 